\title{
TERAPI KEPERAWATAN TERHADAP KOPING KELUARGA PASIEN SKIZOFRENIA
}

\author{
Irene Febriany Mamo Kitu*, Meidiana Dwidiyanti, Diyan Yuli Wijayanti \\ Program Studi Magister Keperawatan, Universitas Diponegoro \\ *ines.kitu@gmail.com
}

\begin{abstract}
ABSTRAK
Permasalahan yang terjadi pada pasien skizofrenia tidak hanya melibatkan pasien itu sendiri tetapi juga melibatkan keluarga sebagai orang terdekat dari pasien tersebut. Keluarga mempunyai beban tersendiri saat merawat anggota keluarga yang mengalami gangguan jiwa. Terapi keperawatan diberikan kepala keluarga agar koping keluarga lebih efektif dalam menghadapi situasi yang ditimbulkan selama perawatan pasien skizofrenia. Literature ini bertujuan untuk mengetahui terapi keperawatan yang dapat digunakan pada keluarga agar koping keluarga lebih efektif. Metode yang digunakan dalam penulisan ini yaitu literature review dengan menggunakan artikel/ jurnal dari tahun 2003 - 2019 dan pencarian artikel melalui Science Direct, Google Scholar dan Pubmed. Tema artikel yang digunakan yaitu terapi keperawatan terkait dengan koping keluarga pasien skizofrenia. Hasil sintesa dari artikel-artikel yang telah ditelusuribahwa terapi keperawatan spesialis mampu mengatasi masalah koping pada keluarga pasien skizofrenia namun perlu adanya penelitian lebih lanjut tentang terapi keperawatan komplementer terhadap masalah koping keluarga pada pasien skizofrenia.
\end{abstract}

Kata kunci: terapi keperawatan, koping keluarga, skizofrenia

\section{NURSING THERAPY TOWARD THE COPING OF FAMILLIES OF SCHIZOPHRENIC PATIENTS: A LITERATURE REVIEW}

\begin{abstract}
The problems that occur in schizophrenic patients not only involve the patient himself but also involve the family as the closest person to the patient. Families have their own burdens when caring for family members who experience mental disorders. Nursing therapy is given by the head of the family so that family coping is more effective in dealing with situations caused during the treatment of schizophrenic patients. This literature aims to determine nursing therapy that can be used in families so that family coping is more effective. The method used in this writing is the literature review by using articles / journals from 2003 - 2019 and searching articles through Science Direct, Google Scholar and Pubmed. The theme of the article used was nursing therapy related to coping with the family of schizophrenic patients. The results of the synthesis of the articles that have been traced that specialist nursing therapy is able to overcome coping problems in the family of schizophrenic patients but need further research on complementary nursing therapy on family coping problems in schizophrenic patients
\end{abstract}

Keywords: nursing therapy, family coping, schizophrenic

\section{PENDAHULUAN}

Skizofrenia adalah suatu penyakit yang mempengaruhi otak dan menimbulkan pikiran, persepsi, emosi, gerakan, dan perilaku yang aneh dan terganggu yang memiliki gejala-gejala positif, seperti waham, halusinasi, disorganisasi pikiran dan bicara, serta perilaku tidak teratur dan gejala-gejala negatif, seperti afek datar, tidak memiliki kemauan, dan menarik diri dari masyarakat atau rasa ketidaknyamanan (Retnowati, 2012).
Keluarga dengan salah satu pasien skizofrenia bisa mengalami konflik yang tinggi, menjadi beban objektif dan subjektif, saling menyalahkan, keterlibatan dalam permusuhan antar anggota keluarga (Pharoah, 2014). Kondisi yang dialami oleh anggota keluarga yang mengalami masalah skizofrenia dapat meningkatkan stres keluarga karena biaya yang harus dikeluarkan oleh keluarga untuk pengobatan pasien dan adanya stigma yang keliru dari masyarakat sehingga keluarga mengganggap bahwa anggota keluarga yang mengalami gangguan skizofrenia adalah sebuah aib (Taufik, 2014). 
Hasil penelitian menunjukkan bahwa sebanyak $66,7 \%$ keluarga yang memiliki anggota keluarga yang mengalami gangguan jiwa mengalami tingkat stres sedang (Mubin, 2013). Hal ini menunjukkan bahwa keluarga ikut terpengaruh dengan masalah yang dialami oleh anggota keluarganyasehingga bila ada anggota keluarga yang mempunyai masalah dalam kesehatan atau keperawatan, maka akan berpengaruh terhadap anggotaanggota keluarga yang lain (Iswanti, 2007). Keluarga sebagai orang terdekat dengan pasien skizofrenia mempunyai peranan yang penting dalam proses penyembuhan (Agustina, 2016). Keluarga memiliki fungsi afektif dalam memenuhi kebutuhan psikologis pasien yaitu dengan memberikan perhatian dan kasih sayang (Suryaningrum, 2013). Seiring dengan proses penyembuhan pada pasien skizofrenia, keluarga akan mengalami kelelahan baik secara fisik dan emosional dan kondisi-kondisi tersebut akan berpengaruh terhadap koping keluarga dan tanpa strategi koping yang baik maka keluarga sulit untuk beradaptasi dengan stresor yang berada disekitar keluarga tersebut (Pharoah, 2014).

Koping keluarga dapat ditingkatkan melalui intervensi fleksibilitas peran keluarga dalam memodifikasi peran keluarga, membuat kelompok sejenis untuk berbagi masalah yang dihadapi dan mencari dukungan spiritual(Rahman, 2016).Koping keluarga yaitu respon yang ditunjukkan oleh keluarga dalam mengatasi stresor yang ada, berusaha untuk memperbaiki masalah yang ada dan beradaptasi dengan situasi yang terjadi (Sutini, 2014). Koping keluarga bila tidak diatasi akan menimbulkan masalah psikologis yang dapat mengakibatkan depresi (Nuraenah, 2012). Penanganan masalah koping pada keluarga pasien skizofrenia dapat diatasi dengan terapi keperawatan. Terapi keperawatan yang dapat digunakan diantaranya terapi spesialis dan terapi komplementer (Stuart, 2007).

\section{METODE}

Metode yang digunakan dalam penulisan ini adalah literature review. Sumber pustaka yang digunakan dalam penyusunan literature review ini menggunakan artikel jurnal dari tahun 20032019. Pencarian jurnal melalui Science Direct, Google Scholar dan Pubmed

\section{HASIL}

Hasil penelitian dari Agustarika (2017) menyebutkan bahwa telah dilakukan terapi keperawatan speialis berupa psikoedukasi yang dilakukn pada keluarga pasien skizofrenia untuk melihat kemampuan keluarga dalam merawat anggota keluarga dengan skizofrenia. Penelitian dilakukan pada 32 responden yang terbagi dari kelompok intervensi dan kelompok kontrol. Hasil yang diperoleh terdapat peningkatan kemampuan keluarga secara bermakna dalam merawat anggota keluarga yang menderita skizofrenia setelah mendapatkan terapi psikoedukasi sebesar 93,8\% pada kelompok intervensi. Penelitian pada terapi keperawatan komplementer yang saat ini dikembangkan, yaitu terapi mindfulness. Penelitian ini menilai efektivitas mindfulness berbasis pengurangan stress dalam mengurangi tingkat stress pada keluarga pasien skizofrenia. Responden dalam penelitian ini adalah anggota keluarga dari pasien skizofreniayang berusia 30-60 tahun yang mengalami stress atau berpotensi mengalami stress. Penelitian ini mendapatkan hasil bahwa adanya penurunan tingkat stress pada keluarga disertai dengan meningkatnya penerimaan dan pemahaman akan kondisi yang sedang terjadi (Putri, 2018).

\section{PEMBAHASAN}

Strategi koping keluarga adalah suatu cara positif yang dilakukan oleh keluarga untuk dapat beradaptasi dengan keadaan yang terjadi baik dalam upaya pemecahan masalah maupun mengurangi stress yang terjadi (Wardaningsih, 2010). Adanya anggota keluarga yang mengalami gangguan jiwa mempunyai beban tersendiri bagi keluarga, dimana keluarga tidak dapat memahami kebutuhan dan tingkah laku pasien serta adanya stigma dari masyarakat sehingga keluarga menjadi stress yang mengakibatkan kelelahan secara fisik dan mental (Wanti, 2016). Terapi keperawatan yang dilakukan pada keluarga terdiri dari terapi spesialis dan terapi komplementer. Terapi spesialis merupakan terapi yang lebih spesifik dari terapi generalis dan dilakukan oleh spesialis dalam keperawatan jiwa. Terapi komplementer merupakan alternatif seperti terapi holistik. Keluarga merupakan sumber social support yang harus memiliki kemampuan dalam memberikan perawatan bagi anggota keluarga yang mengalami masalah sehingga perlu membentuk koping yang adaptif untuk dapat mengoptimalkan peran keluarga dalam 
system keseluruhan untuk mengurangi beban keluarga baik secara fisik maupun mental (Agustin, 2015).

Terapi spesialis dapat diterapkan dalam keluarga untuk mengatasi koping keluarga. Terapi spesialis yang digunakan salah satunya adalah psikoedukasi keluarga. Psikoedukasi keluarga dapat membantu keluarga dalam meningkatkan pengetahuan keluarga tentang gangguan jiwa yang dialami oleh anggota keluarga agar dapat memaksimalkan fungsi keluarga (Liyanovitasari, 2017). Terapi psikoedukasi keluarga dapat memperkuat strategi koping keluarga untuk mengatasi perubahan mental pada anggota keluarga yang mengalami gangguan jiwa serta tetap mempertahankan keberadaan anggota keluarga dalam masyarakat (Kartika, 2017). Intervensi pada psikoedukasi keluarga berupa pemberian informasi dan edukasi dengankomunikasi terapeutik, sehingga dalam pelaksanaannya akan membantu keluarga dalam mengidentifikasi dan merubah keadaan maladaptif untuk meningkatkan kemampuan keluarga dalam penyelesaian masalah (Qolina, 2017).

Intervensi komplementer yang digunakan pada koping keluarga saat ini adalah terapi pemusatan perhatian (mindfulness). Mindfulness merupakan suatu kesadaran karena adanya perhatian pada tujuan, terjadi pada saat ini dan tidak menghakimi. Mindfulness dapat membantu mengurangi dimensi negatif, seperti: stres, gejala deperesi, kecemasan serta meningkatkan kualitas hidup (Baer, 2003). Mindfulness merupakan terapi komplementer dalam keperawatan karena terbukti efektif pada penyakit mental, depresi, pencegahan kekambuhan, kecemasan, gangguan stres pasca trauma, gangguan makan dan penyalahgunaan zat (Martinez, 2019). Mindfulness mempunyai tiga komponen utama, yaitu kesadaran (awareness), pengalaman saat ini (present experience) dan penerimaan (acceptance) sehingga suatu tindakan yang dilakukan secara mindfulness bisa mendorong seseorang untuk bisa berempati terhadap apayang diamati (Umniyah, 2009).

Intervensi mindfulness membantu memfasilitasi individu untuk belajar menerima setiap keadaan dengan terbuka dan tanpa penilaian termasuk dalam keadaan yang penuh tekanan (Chielsa, 2011). Terapi mindfulness yang diterapkan pada pengasuh atau keluarga lansia dengan demensia terbukti membantu merefleksikan pengalaman yang telah dilewati oleh keluarga sehingga keluarga lebih percaya diri dalam memberikan perawatan yang lebih baik (Triyono, 2018). Penerapan terapi mindfulness pada pasien skizofrenia juga mendapatkan hasil bahwa adanya hubungan yang kuat antara mindfulness dan psikologis yang terkait dengan fungsi adaptif (Tabak, 2015).

\section{SIMPULAN}

Koping keluarga yang baik akan berdampak baik bagi kondisi anggota keluarga yang menderita skizofrenia. Terapi generalis, terapi spesialis dan terapi komplementer dapat membantu meningkatkan koping keluarga agar keluarga dapat menghadapi situasi penuh tekanan yang terjadi dan tetap berusaha membantu proses penyembuhan anggota keluarga yang mengalami gangguan jiwa.

\section{DAFTAR PUSTAKA}

Agustina, N. W., Handayani, S. (2016). Peningkatan Kemampuan Keluarga Merawat Pasien Skizofrenia Dengan Gejala Halusinasi Melalui Terapi Suportif Ekspresif. Motorik: 11:54-63

Agustin, I. M, At Al. (2015). Penerapan Tindakan Keperawatan : Terapi Generalis Terhadap Ketidakberdayaan Pada Lansia. Jurnal Ners Vol.10 No. 2

Agustarika, B., Raka. I. M. (2017). Pengaruh Psikoedukasi Keluarga Terhadap Kemampuan Keluarga Dalam Merawat Anggota Keluarga Dengan Skizofrenia Di Kota Sorong. E-Journal Nursing Arts Vol 10, 11 (02).

Baer, R. A. (2003). Mindfulness Training As A Clinical Intervention;(1998):125-43

Chielsa, A, Malinowski, P. (2011). Mindfulness-Based Approaches: Are They All The Same? Journal Of Clinical Psychology

Iswanti, D. I. (2007). Koping Keluarga Terhadap Anggota Keluarga Yang Mengalami Ketergantungan Narkoba diwilayah Kota Semarang. Volume 1, Nomor 1 
Kartika R, At Al. (2017). Pengaruh Terapi Psikoedukasi Keluarga Terhadap Self Efficacy Keluarga Dan Sosial Okupasi Klien Schizophrenia. Jkp- Vol. 5 No. 2

Liyanovitasari., Noorhamdani., Astari, M. A. (2017). Pengaruh Terapi Suportif Kelompok Terhadap Beban dan Mekanisme Koping Keluarga Dalam Merawat Pasien Skizofrenia, Nurseline Journal: Volume 2 No.2

Martinez A., Masluk B., Montero, M. J., Navarro-Gil, M. T., Magallo, R. (2019). Validation Of Five Facets Mindfulness Questionnaire - Short Form, In Spanish , General Health Care Services Patients Sample : Prediction of Depression Through Mindfulness Scale

Mubin, M. F., Andriani, T. (2013). Gambaran Tingkat Stres Pada Keluarga Yang Memiliki Penderita Gangguan Jiwa di RSUD Dr. H. Soewondo Kendal

Nuraenah. (2014). Hubungan Dukungan Keluarga Dan Beban Keluarga Dalam Merawat Anggota Keluarga Dengan Riwayat Perilaku Kekerasan di Rs. Jiwa Islam Klender Jakarta Timur. Jurnal Keperawatan Jiwa Vol. 2 No.1

Pharoah, F., Mari, J., Rathbone, J., Wong, W. (2014). Family Intervention For Scihozophrenia. Eur Pmc Funders Gr

Putri,U. N., Bintarib, D. R. (2018).MindfulnessBased Stress Reduction (Mbsr) For Reducing Stress Among Informal Caregivers of Schizophrenia Outpatients. Advances In Social Science, Education And Humanities Research (Assehr), Volume 135

Qolina, E. (2017). Pengaruh PsikoedukasiKeluarga Terhadap Ansietas Dan Depresi Keluarga Yang Mempunyai Anak Dengan Autis di Sekolah Khusus Autis Harapan Utama Ananda Depok. Jurnal Jkft Vol 2

Rahman, A., Marchira, C., Rahmat, I. (2016). Peran Dan Motivasi Perawat Kesehatan Jiwa Dalam Program Bebas Pasung: Studi Kasus Di Mataram. Bkm J Community Med Public Heal
Retnowati, R., Aat, S., Metty, W. (2012). Strategi Koping Keluarga Dalam Merawat Anggota Keluarga Penderita Skizofrenia di Instalasi Rawat Jalan Rumah Sakit Jiwa Provinsi Jawa Barat

Triyono, H. G, At Al. (2018). Pengaruh MindfulnessTerhadap

CaregiverBurdenLansia Dengan

Demensia di Panti Wreda. Jurnal Ilmu Keperawatan Komunitas Vol. 1 No.1

Umniyah,. Afiatin, T. (2009). Pengaruh Pelatihan Pemusatan Perhatian (Mindfulness) terhadap Peningkatan Empati Perawat. Jurnal Intervensi Psikologi Vol. 1 No. 1

Wanti Y, At Al. (2016). Gambaran Strategi Koping Keluarga Dalam Merawat Anggota Keluarga Yang Menderita Gangguan Jiwa Berat. Vol.4 No.1

Wardaningsih S, At Al. (2010). Gambaran Strategi Koping Keluarga Dalam Merawat Pasien Skizofrenia di Wilayah Kecamatan Kasihan Bantul. Mutiara Medika Vol .10 No. 1

Suryaningrum , S., Wardani, I. Y. (2013). Hubungan Antara Beban Keluarga Dengan Kemampuan Keluarga Merawat Pasien Perilaku Kekerasan di Poliklinik Rumah Sakit Marzoeki Mahdi Bogor. J Keperawatan Jiwa.

Stuart \& Sundeen. (2007). Buku Saku Keperawatan Jiwa. Jakarta: EGC

Tabak, N. T. (2016). Mindfulness In Schizophrenia: Association With SelfReported Motivation, Emotion Regulation, Dysfunctional Attitudes And Negative Symptom. Hhs Public Access Schizophr Res. Author Manuscript

Taufik, Y., Mamnu'ah. (2014). Hubungan Dukungan Keluarga Dengan Tingkat Kekambuhan Pada Pasien Skizofreni di Poliklinik Rumah Sakit Jiwa Grhasia DIY 